\title{
Analysis of Traffic Sign Asset Management Scenarios
}

\author{
Elizabeth Allison Harris \\ Graduate Research Assistant \\ Department of Civil, Construction, and Environmental Engineering \\ North Carolina State University \\ Raleigh, NC 27695-7908 \\ Telephone 919-515-6456, Fax 919-515-7908 \\ Email liz harris@ncsu.edu \\ William Rasdorf, Ph.D., P.E., Professor \\ Department of Civil, Construction, and Environmental Engineering \\ North Carolina State University \\ Raleigh, NC 27695-7908 \\ Telephone 919-515-7637, Fax 919-515-7908 \\ Email rasdorf@eos.ncsu.edu
}

Joseph E. Hummer, Ph.D., P.E., Professor

Department of Civil, Construction, and Environmental Engineering

North Carolina State University

Raleigh, NC 27695-7908

Telephone 919-515-7733, Fax 919-515-7908

Email hummer@eos.ncsu.edu

Chunho Yeom

Incheon Bridge Construction Office

Korea Highway Corporation

Incheon, Korea

Telephone +82-32-850-4266, Fax +82-32-850-4269

Email yeomike@freeway.co.kr

Word Count: 5507 Words +3 Figures and Tables $=6257$

Key Words: sign, retroreflectivity, asset management, simulation, maintenance

Submitted: March 30, 2007 


\begin{abstract}
Minimum traffic sign retroreflectivity standards proposed for the Manual on Uniform Traffic Control Devices by the Federal Highway Administration (FHWA) will present numerous management challenges to state and local departments of transportation (DOTs) responsible for traffic sign assets. These DOTs are looking at how to comply with the standard while minimizing sign maintenance costs.

This paper presents an analysis of several traffic sign retroreflectivity maintenance methods using a sign asset management simulation based on inspection and sign data gathered in the field. The simulation evaluated 30 sign asset management scenarios in terms of annual maintenance cost per sign and percent of traffic signs not compliant with the proposed FHWA standard.

The simulation results found that higher costs for sign maintenance generally resulted in a lower percentage of non-compliant signs. However, for some scenarios using the visual nighttime inspection method, lower percentages of non-compliant signs were found even with relatively low maintenance costs per sign. Increasing the maintenance cost per sign by $10 \%$ resulted in approximately a $10 \%$ or more reduction in the number of non-compliant signs.

It is recommended that DOTs implement a 100\% Type III sign replacement policy because Type I signs have a greater lifecycle cost than Type III signs. DOTs need to allocate an adequate annual budget for sign replacement and should establish their own minimum retroreflectivity standards. The sign asset management simulation developed as part of this study could be modified so that its use can be extended to other DOTs.
\end{abstract}

\title{
INTRODUCTION
}

Traffic signs are an essential component of the transportation asset base. To ensure their proper performance it is imperative that Departments of Transportation (DOTs) have effective traffic sign evaluation and replacement programs to significantly reduce safety risks to motorists. One of the key sign evaluation factors for nighttime driving is retroreflectivity, measured by a coefficient of retroreflection. The coefficient of retroreflection $\left(R_{a}\right)$ is the ratio of the light which the sign reflects to a driver (cd) to the light which illuminates the sign (lx) per unit area $\left(\mathrm{m}^{2}\right)$. In layman's terms it is a measure of how well the sign can be seen at night.

The implementation of minimum retroreflectivity standards in the Manual on Uniform Traffic Control Devices (MUTCD) (1) will present several issues to DOTs responsible for traffic sign replacement and maintenance. The proposed standards specify that the minimum retroreflectivity for white and yellow ground-mounted signs is $50 R_{a}$ and $7 R_{a}$ for red and green signs. DOTs will need to evaluate whether their current sign asset management practices will ensure compliance with the proposed standards. If not, they will need to develop an improved sign asset management system. When the proposed standards are finally adopted, both compliance (for the safety and well being of the public) and proof of compliance (to protect against lawsuits) will be necessary. An effective management strategy can support both.

The FHWA has developed several retroreflectivity maintenance strategies that DOTs can implement to comply with the proposed standards (2). These retroreflectivity maintenance strategies can be divided into two main groups--assessment methods and management methods-and are further broken down as follows:

- Assessment Methods

○ Visual Nighttime Inspection Method 


\section{○ Measured Retroreflectivity Method \\ - Management Methods \\ ○ Expected Sign Life Method \\ - Blanket Replacement Method \\ ○ Control Sign Method}

Assessment methods ensure compliance with the proposed standards by evaluating all signs in place on the roadways. The visual nighttime inspection method uses human observers to visually judge at night whether a sign is compliant (in compliance with the minimum standard). Human observers need some training in order to correctly judge the retroreflectivity of a sign and to adhere to established inspection procedures. Generally, the nighttime visual inspection is conducted at regular highway speeds from the travel lane (right lane) using the low beam headlights. The human observers qualitatively evaluate sign retroreflectivity at a viewing distance that would provide a driver adequate time to respond to the message of the sign.

Alternatively, the measured retroreflectivity method uses a retroreflectometer to measure all signs. At least four retroreflectivity readings are taken during the daytime and the average retroreflectivity value for the sign is compared to the established minimums for that particular sign. For both of these methods, if a sign's retroreflectivity is determined to be non-compliant (below the minimum standard) then it will be replaced.

Management methods, on the other hand, do not involve evaluating every sign in place on the roadways. Instead, management methods predict how long signs with similar characteristics (such as sign color and sheeting type) will maintain an above-standard retroreflectivity, also known as the sign life. When the end of the sign's lifetime has been reached, it should be replaced. The expected sign life method calculates a sign life from known sign retroreflectivity deterioration rates for combinations of sign sheeting color and sheeting type. The expected sign life method requires tracking the age of signs either by using sign installation date labels on the back of each sign or maintaining a sign asset management system that can identify the age of every sign in the jurisdiction. When an individual sign's retroreflectivity is predicted to fall below the minimum it should be replaced.

The blanket replacement method replaces all signs along a corridor, within an area, or of the same sign and sheeting type at intervals based on the expected sign life of the signs. For blanket replacement, the replacement interval can be selected by DOTs based on previous sign deterioration experience or the sign sheeting manufacturer's warranty period. Once the time interval has elapsed, all signs within the corridor/area/type are replaced, regardless of age.

The control sign method uses signs either in a controlled study yard or a sample of signs from the field to determine sign life. The control sample of signs is used to represent all of the signs in an agency's jurisdiction. The sampling plan should ensure that the quantity and diversity of signs sampled represents the agency's sign population and that there is monitoring of sign retroreflectivity at regular intervals. When a control sign's retroreflectivity is measured by a retroreflectometer and is found to fall below the minimum level, all similar signs in the field should be replaced. All three of these management methods require basic knowledge of the age and performance characteristics of each sign on the roadways.

The study discussed in this paper evaluated traffic sign asset management practices in North Carolina. The North Carolina Department of Transportation (NCDOT) owns and maintains approximately 78,800 miles of roadway (77\% of all road miles in NC) and is the second largest state-owned system in the United States (3). As a result, NC has the challenge of 
maintaining over one million signs on its roadways (4). However, many of the findings from this study are germane to DOTs in other states which use or will use similar methods to tackle similar problems.

Currently, the NCDOT uses the Visual Nighttime Inspection Method as its retroreflectivity maintenance strategy. The authors conducted a study for the NCDOT to quantitatively evaluate their nighttime qualitative inspection process and to simulate alternative sign asset management scenarios. As part of the study, the authors modeled the performance of NCDOT sign inspectors, determined sign retroreflectivity performance with respect to age, determined external factors that affect sign performance, and developed a sign asset management simulation program. This paper will discuss how estimated costs and sign asset conditions were calculated by the sign asset management simulation program using 30 sign asset management scenarios.

\section{SIGN ASSET MANAGEMENT SIMULATION}

The sign asset management simulation program is a macroscopic simulation that models how cohorts of signs with similar attributes decline in retroreflectivity and are replaced over time. The simulation calculates the annual condition of the sign population and the annual sign turnover. The signs are placed into cohorts based on their retroreflectivity value, sign sheeting type (Type I or Type III as classified by the American Society for Testing and Materials) and background sign color (white, yellow, red, and green) in a start year (n). The sign asset management simulation uses a Microsoft ${ }^{\circledR}$ Excel® spreadsheet to model sign condition in the field over time using field-measured simulation factors for sign deterioration rate, replacement rate, and damage rate. The simulation factors were obtained from NC sign data for groundmounted signs and the simulation results were validated by matching them with current field sign data and sign financial data from the NCDOT.

\section{Asset Management Parameters and Simulation}

Several parameters are used in the sign asset management simulation to account for the various retroreflectivity maintenance strategies, sign damage and replacement rates, and sign replacement alternatives. After these parameters are input, the simulation is run for a number of years until it stabilizes (i.e., changes very little from one year to the next) to facilitate comparisons.

\section{Inspection Frequency and Rejection Threshold}

The sign asset management simulation implements the various retroreflectivity maintenance strategies using sign rejection thresholds and inspection frequencies as two program parameters. A sign rejection threshold is either the retroreflectivity value or the age at which a sign would be rejected. For example, if the rejection threshold is a retroreflectivity value of $40 \mathrm{~cd} / \mathrm{lux} / \mathrm{m}^{2}$, then when a sign with retroreflectivity less that $40 \mathrm{~cd} / \mathrm{lux} / \mathrm{m}^{2}$ is "inspected" in the simulation, it is supposed to be "rejected" and the replacement rate is adjusted accordingly. If the rejection threshold is a sign age, such as 10 years, then a sign would be "rejected" in the simulation once the sign is 11 years old. How often signs are "inspected" in the simulation is based on the inspection frequency, which varies from annually to every three years. In NC, the NCDOT inspects interstate signs annually, signs on primary roads every two years, and signs on 
secondary roads every three years. Since most signs are on rural, secondary roads, the average inspection frequency in $\mathrm{NC}$ was found to be every 2.64 years (5).

\section{Damage and Replacement Rates}

Another parameter in the simulation is the number of damaged signs. Damage includes both natural effects (such as tree sap) and vandalism (such as paintball and gun shots). The damage rates for each sign color and sheeting type were calculated from the authors' field study for NCDOT and from NCDOT financial and asset inventory data (6). In the simulation damaged signs are added to the number of signs that are "rejected" for low retroreflectivity or sign age.

The final key parameter is sign replacement rate. The sign replacement (turnover) rate is the ratio of the total number of signs "rejected" by sign crews to the total number of signs inspected by the sign crew. Visual sign inspection is imperfect, of course, so some signs above the threshold described above will be rejected and some signs below the threshold will be retained. This is accounted for by the replacement rate. The total number of signs "rejected" is the sum of the number of signs "rejected" for meeting a rejection threshold and the number of damaged signs calculated from the damage rates. After the total number of "rejected" signs is determined, the simulation applies the resulting replacement rates to each sign cohort based on distributions observed during the authors' field study for NCDOT (5).

\section{Replacement Alternatives}

When signs are replaced in the simulation, they can be replaced by either a Type I (enclosed lens) or Type III (encapsulated lens) sign. The majority of road signs in the U.S. and NC are either Type I or Type III $(7,5)$. This choice is represented in the simulation as the Type I to Type III conversion rate, with $100 \%$ indicating all signs replaced with Type III and $0 \%$ indicating all signs replaced with Type I. The NCDOT has instituted a policy of 100\% Type III sign replacement. Upgrading Type I signs to Type III signs improves safety and results in a benefit to cost ratio greater than $1.0(8)$. During the field study the authors' found an average Type I to Type III conversion rate of $89 \%$ as some units are apparently clearing out existing stocks of Type I signs (5).

\section{Simulation and Stabilization}

After new signs are assigned to the appropriate sign cohort in the simulation and the declines in retroreflectivity for signs not replaced are calculated, the simulation then predicts the cohort distribution of the sign population in the next year, year $n+1$. When the sign distribution of year $\mathrm{n}$ is essentially the same as year $\mathrm{n}+1$, the simulation is considered to be stabilized.

The stabilized average cohort distribution can then be used to compare different sign asset management scenarios. The stabilized sign cohort distribution models the condition of all signs in the field. Of most interest for budgeting purposes is the number of new signs installed each year in the simulation. More detailed information about the sign asset management simulation can be found in Hummer et. al. (9).

\section{Inspection and Replacement Cost}

The annual sign retroreflectivity maintenance cost in the simulation is a function of the inspection frequency and average replacement sign material cost. Every time a sign is inspected (using either of the assessment methods) there is a labor cost associated with the inspection. The 
authors calculated an inspection cost of $\$ 0.55$ per sign for the visual nighttime inspection method and $\$ 2.80$ per sign for the measured retroreflectivity method, based on data from the authors' field study and from a NC sign inventory $(4,5)$.

The visual nighttime inspection cost per sign was calculated using an assumed individual sign crew worker wage of $\$ 22$ per hour and a sign crew individual visual inspection rate of 40 signs/hour that was calculated from the authors' field study (5). Dividing the hourly wage by the number of signs inspected per hour yielded a visual nighttime inspection cost of $\$ 0.55$ per sign.

For the measured retroreflectivity method, the personnel costs per sign were calculated to be the individual sign crew worker wage of $\$ 22$ per hour divided by the measured retroreflectivity inspection rate of 8.3 signs/ person-hour derived from study observations (5). This resulted in a labor cost per sign of $\$ 2.65$. The higher cost per sign for the measured retroreflectivity method is mainly due to the reduced number of signs that can be evaluated per hour. The total cost per sign for the measured retroreflectivity method also included the retroreflectometer equipment cost per sign. The equipment cost per sign was calculated by dividing the total statewide equipment cost per year by the number of signs inspected per year in the state. In the case of the NCDOT, the authors calculated that 56 retroreflectometers would be needed at a cost of $\$ 10,000$ each, and that these retroreflectometers would have a service life of 10 years. This resulted in an equipment cost per year of $(56 \times \$ 10,000) / 10=\$ 56,000$. The number of signs inspected per year was calculated by dividing the total number of signs in NC $(970,000)$ obtained from a NC sign inventory (4) by the average NCDOT inspection frequency of every 2.64 years (5). The equipment cost per sign was calculated to be $\$ 56,000 /(970,000 / 2.64)=\$ 0.15$. Therefore the total cost per sign for the measured retroreflectivity method is $\$ 2.65+\$ 0.15=\$ 2.80$. The inspection and replacement costs do not include vehicle costs. In the future the authors plan to conduct a more detailed cost analysis.

The authors also determined average replacement sign material costs for each sign sheeting type and color. The average costs were based on the cost of the sign materials and installation for the most commonly installed sign of each color. For example, the most commonly installed red sign is a STOP sign, with an installed cost of $\$ 40.16$ for a Type I sign and $\$ 65.01$ for a Type III sign. Signs are replaced in the simulation due to loss of retroreflectivity or damage. The simulation does not include sign maintenance costs associated with software, data processing, program administration, and general sign maintenance (cleaning, realignment).

\section{SIMULATION SCENARIOS}

The authors tested 30 sign asset management scenarios. These were created by changing the asset management parameters described in the last section. These parameters also included retroreflectivity maintenance strategy, rejection threshold, Type I to Type III conversion rate, and inspection frequency. The scenarios were designed to examine the visual nighttime inspection method, the measured retroreflectivity method, the expected sign life method, and the blanket replacement method.

The control sign method was the only retroreflectivity maintenance strategy not explicitly tested in the scenarios because its parameters are identical to the expected sign life method. The two methods have the same rejection threshold, which is the FHWA proposed minimum standard of approximately $\mathrm{Ra}=50$ for white and yellow signs and $\mathrm{Ra}=7$ for red and green signs (2). The only difference between the expected sign life method and the control sign method is that the expected sign life method uses a sign retroreflectivity deterioration model to determine if signs 
are compliant while the control sign method uses the deterioration of control signs. The costs associated with the control sign method will be slightly higher than the expected sign life method since it requires ongoing inspection of control signs. The implementation of a "sign farm" to monitor control signs could aid in generating data on control sign method costs and parameters.

The majority (24 out of 30 ) of the sign asset management scenarios tested in this study represented the visual nighttime inspection method because this method is currently in use by the NCDOT and has many possible values for the key inputs. Furthermore, the measured retroreflectivity method is simply cost prohibitive at the present time. Table 1 shows the key parameters used in all 30 sign asset management scenarios. The first column of this table assigns an identification number to each scenario. The second through fifth columns contain the maintenance strategy, rejection threshold, conversion rate, and inspection frequency previously discussed. The sixth column shows the annual retroreflectivity maintenance cost per sign in U.S. dollars and the seventh column contains the percent of signs that are non-compliant, or, in other words, below the proposed FHWA minimum traffic sign retroreflectivity standards.

Scenarios 1-16 represent the visual nighttime inspection method with varying rejection thresholds and inspection frequencies. The key parameters of the first scenario represent the current sign asset management practices in NC as determined by the authors' field study. That is, the NCDOT maintenance strategy is the visual nighttime inspection method, its rejection threshold for $\mathrm{Ra}$ is 20 for white and yellow signs and 4 for red and green signs, its Type I to Type III conversion rate is $89 \%$, and its inspection frequency is an average of 2.64 years. Scenarios 2-4 change only the inspection frequency while keeping all of the other current NC key parameters the same. Scenarios 5-8, 9-12, and 13-16 model what would happen if the rejection threshold is incrementally increased (from 20 to 50 by 10 for white and yellow and from 4 to 7 by 1 for red and green) up to the proposed FHWA standard (50 and 7, respectively).

Scenarios 17-20 evaluate the measured retroreflectivity method at four different inspection frequencies, including the current average NCDOT inspection frequency of 2.64. The rejection thresholds and the inspection frequencies are the same here as for scenarios 13-16. The difference lies only in the maintenance strategy chosen, but this difference significantly affects the annual maintenance cost per sign.

Scenarios 21-28 test how changing the Type I to Type III conversion rate will affect the annual sign maintenance cost and the percentage of non-compliant signs. These eight scenarios were designed to be easily compared with scenarios 1-4, since the only difference in inputs between them is the conversion rate. The increased cost of scenarios 26-28 over scenarios 2-4 and 22-24 is due to the use of only Type I signs in scenarios 26-28. Replacing the Type I signs more frequently (due to the fact that Type I signs deteriorate earlier than Type III signs) seems to cost more than the extra cost of a Type III sign. Montebello and Schroeder also found that long life sheetings could lead to lower life-cycle costs than short-life sheetings (10).

Scenario 29 in Table 1 represents the expected sign life method, with a rejection threshold based on the FHWA proposed minimum retroreflectivity standards and a Type I to Type III conversion rate of $100 \%$ (all new signs Type III only). The rejection thresholds for Scenario 29 were chosen based on when sign deterioration models created during the NCDOT study predicted that signs would be below the minimum standards (5). Based on the deterioration models, all Type III signs were predicted to be non-compliant after 17 years and Type I signs were predicted to be non-compliant after 12, 3, 5, and 11 years for white, yellow, red, and green signs respectively. 
Scenario 30, the blanket replacement method scenario, uses an age-based rejection threshold instead of retroreflectivity values. The thresholds are based on a warranty period of 7 years for Type I signs and a conservative lifetime of 12 years for Type III signs. This scenario also has a $100 \%$ Type I to Type III conversion rate.

\section{RESULTS}

The "ideal" sign asset management scenario for the NCDOT, or any other DOT, would minimize both maintenance costs and the percentage of signs in a non-compliant condition. The definition of "ideal" is dependent on the maximum percentage of non-compliant signs a DOT will accept, on the limitations of the DOT budget, and on the abilities of the sign inspectors (in the case of visual nighttime inspection).

Each of the 30 sign asset management scenarios were simulated using the simulation program described before. Scenario 1, visual nighttime inspection with the current NCDOT sign asset management parameters, resulted in an annual cost per sign of $\$ 3.43$ and in $20.8 \%$ of all signs being non-compliant. The percentage of non-compliant signs in Scenario 1 can serve as a benchmark for evaluating the other scenarios, since it would be illogical for the NCDOT to select an alternative scenario that results in worse sign conditions than currently exist. For this reason, scenarios 4, 24, 25, 27, and 28 should be eliminated as alternatives that could be considered for implementation. In a similar manner, Scenarios 3, 23, and 26 could also be eliminated as offering little improvement on the current method. These eight eliminated scenarios are all visual nighttime inspection method scenarios.

The change in sign asset management practices that would probably be the easiest for NCDOT to implement is $100 \%$ Type I to Type III conversion, which is represented by Scenario 21. The increase in conversion rate from $89 \%$ to $100 \%$ improves sign condition by $0.2 \%$ and increases annual sign maintenance costs by one cent per sign (though short-term costs are higher (5)). Since the improvement in sign condition is slight, other changes should be considered, and Scenario 21 should be eliminated from consideration.

One way to approach interpreting the scenario results is to pick an acceptable percentage of non-compliant signs and to find the increase in sign maintenance costs and changes in sign asset management strategies associated with the improvement in sign compliance. To achieve approximately $10 \%$ or fewer non-compliant signs, the least expensive scenarios are $5,9,12,13$, and 16. All of these scenarios use the visual nighttime inspection method.

Table 2 compares Scenario 1 with Scenarios 5, 9, 12, 13, and 16. Essentially this table shows that it is possible to cut the number of non-compliant signs in half with only a $10 \%$ increase in cost. Another consideration is the rejection threshold for each scenario, since it is more difficult for the NCDOT to train sign inspectors to have a visual retroreflectivity rejection threshold closer to the proposed standard. Considering training, the scenarios that may be the most acceptable to the NCDOT are Scenarios 5 and 12 which theoretically require less of an improvement in training while reducing the percentage of non-compliant signs to approximately $10 \%$ or less and increasing maintenance costs per sign by less than $10 \%$.

Figure 1 can also assist in visualization of the simulation scenario results at various sign condition levels. Figure 1 plots the annual maintenance cost per sign versus the percentage of non-compliant signs for the 30 scenarios and shows the best-fit polynomial curve through the data points. In the figure the retroreflectivity maintenance strategy of each scenario is identified by an assigned symbol. Scenarios 29 and 30, the expected sign lifetime and blanket replacement methods, respectively, result in a negligible percentage of non-compliant signs in Figure 1 but 
are also among the most expensive in sign maintenance cost (\$5.09 and \$6.22). Also in Figure 1 the four measured retroreflectivity method scenarios inhabit the upper left portion of the chart, which corresponds to fewer non-compliant signs but higher maintenance costs.

The remaining 24 points in Figure 1 represent the visual nighttime inspection method scenarios, most of which have a low annual maintenance cost between $\$ 3$ and $\$ 4$ per sign and a large spread in non-compliant sign percentage. The middle of the dashed best-fit curve (created from all 30 scenarios) shows how the annual maintenance cost remains nearly constant as the percentage of non-compliant signs increases from $15 \%$ to $30 \%$. This means that it should not cost much more than Scenario 1 to reduce the percent of non-compliant signs to $15 \%$, and slightly more to reduce the percent of non-compliant signs to $10 \%$, as demonstrated in Table 2 .

\section{CONCLUSIONS}

The goal of analyzing the 30 sign asset management scenarios was to predict how NCDOT, and in turn other DOTs, can minimize sign asset costs while maintaining a high level of safety on local and state roads. Figure 1 illustrates that higher costs for sign maintenance generally result in a lower percentage of non-compliant signs. However, for some cases, a lower number of noncompliant signs is expected even with a relatively low maintenance cost per sign. For example, scenarios $5,9,12,13$, and 16 all cost only about $10 \%$ per sign more than scenario 1 (NCDOT current practice), while reducing the percent of non-compliant signs from 21 to 10 or less.

Looking at the scenario results, the visual sign inspection method appears to be the most cost-effective retroreflectivity maintenance strategy at the present time with technology that is available today. The visual sign inspection method in scenarios 13-16 is able to yield a slightly lower percentage of non-compliant signs than the measured retroreflectivity method in scenarios 17-20 but with lower costs per sign. The reason that Scenarios 13-16 have a slightly lower percentage of non-compliant signs is due to imperfect sign inspectors replacing some signs while they are still well above the rejection threshold with new signs. In the measured retroreflectivity method (Scenarios 17-20), only signs that have been quantitatively measured to be below the FHWA minimums are replaced. The primary advantage of the measured retroreflectivity method is that the actual retroreflectivity of each sign is known, which with recordkeeping could defend DOTs from sign-related lawsuits and also quantitatively prove compliance with the proposed FHWA standards.

As long as the cost of training sign inspectors to use a higher visual inspection retroreflectivity standard is less than the increased labor costs of the measured retroreflectivity method, training sign inspectors can be a cost-effective way to reduce the number of noncompliant signs on the roads. The additional training, and resulting increase in rejection threshold increases the annual cost per sign because signs will be left in service in the field for a shorter duration of time. With a lower rejection threshold, a sign could theoretically remain in the field a few years longer (with a resulting decreased lifecycle cost) than with a higher rejection threshold.

For a DOT that seeks nearly a $100 \%$ compliance with the proposed FHWA minimum retroreflectivity standards, the expected sign lifetime method can be used. For the NCDOT, this method would result in a projected $48 \%$ increase (approximately $\$ 1.60$ per sign for the NCDOT) in sign maintenance costs. The expected sign lifetime method is still much less expensive than the other methods that produce very high levels of compliance (the blanket replacement method and the retroreflectivity measurement methods). The cost of the expected sign life method is similar to the cost of annual visual nighttime inspections with a rejection threshold at the FHWA 
Standard (Scenario 14). The costs associated with the control sign method could be better estimated with a "sign farm' or other system of sign sampling in place.

The NCDOT policy of replacing all "rejected" signs with new Type III signs is an effective strategy for reducing the percentage of non-compliant signs. In the other extreme case of 0\% Type I to Type III conversion (Scenario 25) the percentage of non-compliant signs rises from $20.8 \%$ (Scenario 1) to $34.8 \%$ with the current inspection frequency of 2.64 years, and there is an increase of 9 cents in long-term average maintenance costs per sign ( $\$ 3.43$ to $\$ 3.52)$. The lifecycle costs for a Type III sign are less than for a Type I sign because although a Type I sign costs $20-40 \%$ less than a Type III sign, Type III signs maintain adequate retroreflectivity approximately 50\% longer than Type I signs. Thus, conversion of Type I to Type III is both beneficial in terms of safety and cost-effective in the long run.

From the scenario results it does not appear that there is a need for the NCDOT to inspect signs more frequently than it currently does, since the cost-effective scenarios 5, 9, 12, 13, and 16 all had an average inspection frequency of between 2.64 years and 3 years. Changing the inspection frequency from every one to every three years decreases the annual cost per sign since inspections occur less frequently, but the percentage of non-compliant signs increases because non-compliant signs remain undetected in the field for a longer time. For the visual nighttime inspection methods, increasing the inspection frequency from every 3 years to annually increases costs by approximately $\$ 1.40$ per sign and at least halves the percentage of non-compliant signs.

\section{RECOMMENDATIONS}

A 100\% Type III sign replacement policy should be used by DOTs in order to decrease their number of non-compliant signs while spending almost the same or less budget long term as with a $0 \%$ conversion rate. Replacing Type I signs more frequently costs more over the lifecycle of a sign than the additional cost of a Type III sign.

Second, DOTs need to allocate an adequate annual budget for sign replacement. Among other things, doing so will ensure that sign inspector decisions are based on retroreflectivity and damage considerations rather than on budgetary considerations. That is, inspectors should be able to reject a non-compliant sign without having to consider whether or not the sign budget will allow such a rejection.

Third, all states should establish their own minimum retroreflectivity standards prior to the implementation of the proposed FHWA minimum standards. This will help the states in implementing a sign replacement procedure to reduce the number of non-compliant signs. When such procedures are successfully implemented in the states, a transition to the common FHWA minimums will be far easier than might otherwise be the case. Furthermore, documented proof of compliance will be available.

Finally, the sign asset management simulation developed as part of this study could be modified so that its use can be extended to other DOTs. In order for the simulation to be used by other DOTs, information on the initial condition of signs, inspector performance, inspection frequency, and damage rates for the jurisdiction being evaluated needs to be collected. The base replacement rates used in the simulation were derived directly from inspector performance field data, or, in other words, how well NC inspectors identified non-compliant signs. Inspection frequencies can be gathered from regional personnel or from existing DOT policies. DOT-wide and/or local damage rates can be generated from DOT financial accounting records and from a sign inventory if the agency tracks sign spending by replacement cause (damage vs. deterioration). It should be noted that there can be variability in these key simulation parameters 
from one locality to another, and from one DOT to another. The authors can make a version of the sign asset management simulation available upon request.

\section{ACKNOWLEDGEMENTS}

The authors would like to thank Kent Langdon of the NCDOT and Danny Stanley of the State of North Carolina Correction Enterprises for providing important financial data for this study. This work was sponsored by the NCDOT, and the authors are grateful for their support. Support was also provided by a National Science Foundation (NSF) Graduate Research Fellowship. The views expressed in this paper are those of the authors and do not necessarily reflect the views of the NCDOT or of NSF. The authors alone are responsible for any errors. This paper does not represent a standard, guideline, or specification of the NCDOT or any other agency.

\section{REFERENCES}

1. Proposed Revision \#2 to the 2003 Edition of the Manual on Uniform Traffic Control Devices. Federal Highway Administration, U.S. Department of Transportation. tcd.tamu.edu/documents/minretro/2005-08-02_PROPOSED_Rev2.pdf Accessed July 29, 2006.

2. Maintaining Traffic Sign Retroreflectivity. FHWA-SA-03-027. Federal Highway Administration, U.S. Department of Transportation. safety.fhwa.dot.gov/roadway_dept/docs/maintain_sign_retro.pdf. Accessed July 29. 2006.

3. Highway Statistics 2004. Table HM-80. Federal Highway Administration, U.S. Department of Transportation. www.fhwa.dot.gov/policy/ohim/hs04/htm/hm80.htm. Accessed July 29, 2006.

4. Kirtley, N., Palmquist, M., and Rasdorf, W. Sign Count Approximation Using Field Inventory Sampling and Calculated Sign Densities for North Carolina. Technical Report, Department of Civil Engineering, NC State University. Raleigh, NC, 2002.

5. Rasdorf, W., Hummer, J. E., Harris, E. A., Yeom, C., and Immaneni, V. P. Designing an Efficient Nighttime Sign Inspection Procedure to Ensure Motorist Safety. Final Report, FHWA/NC/2006-08, North Carolina Department of Transportation, Raleigh, N.C, 2006.

6. Immaneni, V. P., Rasdorf, W., Hummer, J. E., and Yeom, C. Field Investigation of Sign Damage Rates and Inspection Accuracy. Journal of Public Works Management and Policy, 2007, in press.

7. Taori, S., and McGee H. W. Impacts of Maintaining Traffic Signs Within Minimum Retroreflectivity Guidelines. In Transportation Research Record: Journal of the Transportation Research Board, No. 1650, TRB, National Research Council, Washington, D.C., 1998, pp. 1927.

8. Ripley, D. A. Quantifying the Safety Benefits of Traffic Control Devices - BenefitCost Analysis of Traffic Sign Upgrades. Proceedings of the 2005 Mid-Continent Transportation Research Symposium, Ames, Iowa, August 2005.

9. Hummer, J. E., Rasdorf, W., Yeom, C., and Harris, E. A. Sign Management Improvement Using Simulation. International Journal of Transportation Research (Part A: Policy and Practice), Elsevier, Submitted 2007. 
10. Montebello, D. and Schroeder, J. Cost Effectiveness of Traffic Sign Materials. Final Report, Report MN-2000-12, Minnesota Department of Transportation, St. Paul, MN, 2000. 
Harris, E.A., Rasdorf, W., Hummer, J.E., and Yeom, C.

\section{LIST OF TABLES AND FIGURES}

TABLE 1 Sign Asset Management Scenarios and Simulation Results

TABLE 2 Comparison of Scenario 1 with Scenarios 5, 9, 12, 13, and 16

FIGURE 1 Annual maintenance cost per sign vs. percentage of non-compliant signs. 
Harris, E.A., Rasdorf, W., Hummer, J.E., and Yeom, C.

TABLE 1 Sign Asset Management Scenarios and Simulation Results

\begin{tabular}{|c|c|c|c|c|c|c|}
\hline \# & $\begin{array}{l}\text { Maintenance } \\
\text { Strategy }\end{array}$ & $\begin{array}{l}\text { Rejection } \\
\text { Threshold }\end{array}$ & $\begin{array}{l}\text { Type I to Type } \\
\text { III Conversion } \\
\text { Rate }(\%)\end{array}$ & $\begin{array}{l}\text { Inspection } \\
\text { Frequency, } \\
\text { Years }\end{array}$ & $\begin{array}{l}\text { Annual } \\
\text { Cost per } \\
\text { Sign }(\$)\end{array}$ & $\begin{array}{l}\text { Non- } \\
\text { compliant } \\
\text { Signs (\%) }\end{array}$ \\
\hline 1 & \multirow{16}{*}{$\begin{array}{l}\text { Visual } \\
\text { Nighttime } \\
\text { Inspection }\end{array}$} & \multirow{4}{*}{$\begin{array}{l}\text { Ra Limit 20: W, Y } \\
\text { Ra Limit 4: R, G } \\
\text { (Current NCDOT) }\end{array}$} & \multirow{4}{*}{$89 \%^{a}$} & $2.64^{b}$ & 3.43 & \\
\hline 2 & & & & 1 & 4.67 & \\
\hline 3 & & & & 2 & 3.72 & \\
\hline 4 & & & & 3 & 3.28 & \\
\hline 5 & & \multirow{4}{*}{$\begin{array}{l}\text { Ra Limit 30: } \mathrm{W}, \mathrm{Y} \\
\text { Ra Limit 5: R, G }\end{array}$} & \multirow{4}{*}{$89 \%^{a}$} & $2.64^{b}$ & 3.79 & \\
\hline 6 & & & & 1 & 4.58 & \\
\hline 7 & & & & 2 & 4.02 & \\
\hline 8 & & & & 3 & 3.59 & \\
\hline 9 & & \multirow{4}{*}{$\begin{array}{l}\text { Ra Limit 40: W, Y } \\
\text { Ra Limit 6: R, G }\end{array}$} & \multirow{4}{*}{$89 \%^{a}$} & $2.64^{b}$ & 3.86 & \\
\hline 10 & & & & 1 & 4.88 & \\
\hline 11 & & & & 2 & 4.09 & \\
\hline 12 & & & & 3 & 3.75 & \\
\hline 13 & & \multirow{4}{*}{$\begin{array}{l}\text { Ra Limit 50: W, Y } \\
\text { Ra Limit 7: R, G } \\
\text { (FHWA Standard) }\end{array}$} & \multirow{4}{*}{$89 \%^{a}$} & $2.64^{b}$ & 3.88 & \\
\hline 14 & & & & 1 & 4.88 & \\
\hline 15 & & & & 2 & 4.11 & \\
\hline 16 & & & & 3 & 3.77 & \\
\hline 17 & \multirow{4}{*}{ Measured Ra } & \multirow{4}{*}{$\begin{array}{l}\text { Ra Limit 50: W, Y } \\
\text { Ra Limit 7: R, G } \\
\text { (FHWA Standard) }\end{array}$} & \multirow{4}{*}{$89 \%^{a}$} & $2.64^{b}$ & 4.72 & \\
\hline 18 & & & & 1 & 7.18 & \\
\hline 19 & & & & 2 & 5.23 & \\
\hline 20 & & & & 3 & 4.50 & \\
\hline 21 & \multirow{8}{*}{$\begin{array}{l}\text { Visual } \\
\text { Nighttime } \\
\text { Inspection }\end{array}$} & \multirow{4}{*}{$\begin{array}{l}\text { Ra Limit 20: W, Y } \\
\text { Ra Limit 4: R, G } \\
\text { (Current NCDOT) }\end{array}$} & \multirow{4}{*}{$100 \%$} & $2.64^{b}$ & 3.44 & \\
\hline 22 & & & & 1 & 4.67 & \\
\hline 23 & & & & 2 & 3.73 & \\
\hline 24 & & & & 3 & 3.29 & \\
\hline 25 & & \multirow{4}{*}{$\begin{array}{l}\text { Ra Limit 20: W, Y } \\
\text { Ra Limit 4: R, G } \\
\text { (Current NCDOT) }\end{array}$} & \multirow{4}{*}{$0 \%$} & $2.64^{b}$ & 3.52 & \\
\hline 26 & & & & 1 & 5.24 & \\
\hline 27 & & & & 2 & 3.97 & \\
\hline 28 & & & & 3 & 3.30 & \\
\hline 29 & $\begin{array}{l}\text { Expected } \\
\text { Sign Life }\end{array}$ & $\begin{array}{l}\text { Ra Limit 50: W, Y } \\
\text { Ra Limit 7: R, G } \\
\text { (FHWA Standard) }\end{array}$ & $100 \%$ & N/A & 5.09 & \\
\hline 30 & $\begin{array}{l}\text { Blanket } \\
\text { Replacement }\end{array}$ & $\begin{array}{l}\text { Type I: Replace } \\
\text { after } 7 \text { years } \\
\text { Type III: Replace } \\
\text { after } 12 \text { years }\end{array}$ & $100 \%$ & N/A & 6.22 & \\
\hline
\end{tabular}

NOTE: ${ }^{a}$ Average over all four sign colors, this is the current NCDOT condition

${ }^{b}$ Average over all four sign colors, two sheeting types and three road types, this is the current NCDOT condition

W: White, Y: Yellow, R: Red, G: Green, Ra: Retroreflectivity, N/A: Not Applicable 
TABLE 2 Comparison of Scenario 1 with Scenarios 5, 9, 12, 13, and 16

\begin{tabular}{llllll}
$\begin{array}{l}\text { Scenario } \\
\#\end{array}$ & $\begin{array}{l}\text { Annual Cost } \\
\text { per Sign (\$) }\end{array}$ & $\begin{array}{l}\text { Non-compliant } \\
\text { Signs (\%) }\end{array}$ & $\begin{array}{l}\text { Additional Cost } \\
\text { over Scenario 1 } \\
\text { (percent) }\end{array}$ & $\begin{array}{l}\text { Inspection } \\
\text { Frequency } \\
\text { (years) }\end{array}$ & $\begin{array}{l}\text { Rejection } \\
\text { Threshold } \\
\text { (W \& Y, R \& G) }\end{array}$ \\
\hline 1 & 3.43 & 20.8 & $0.0 \%$ & 2.64 & 20,4 \\
5 & 3.79 & 11.3 & $10.5 \%$ & 2.64 & 30,5 \\
9 & 3.86 & 9.2 & $12.5 \%$ & 2.64 & 40,6 \\
12 & 3.75 & 10.4 & $9.3 \%$ & 3 & 40,6 \\
13 & 3.88 & 8.7 & $13.1 \%$ & 2.64 & 50,7 \\
16 & 3.77 & 9.8 & $9.9 \%$ & 3 & 50,7 \\
\hline
\end{tabular}




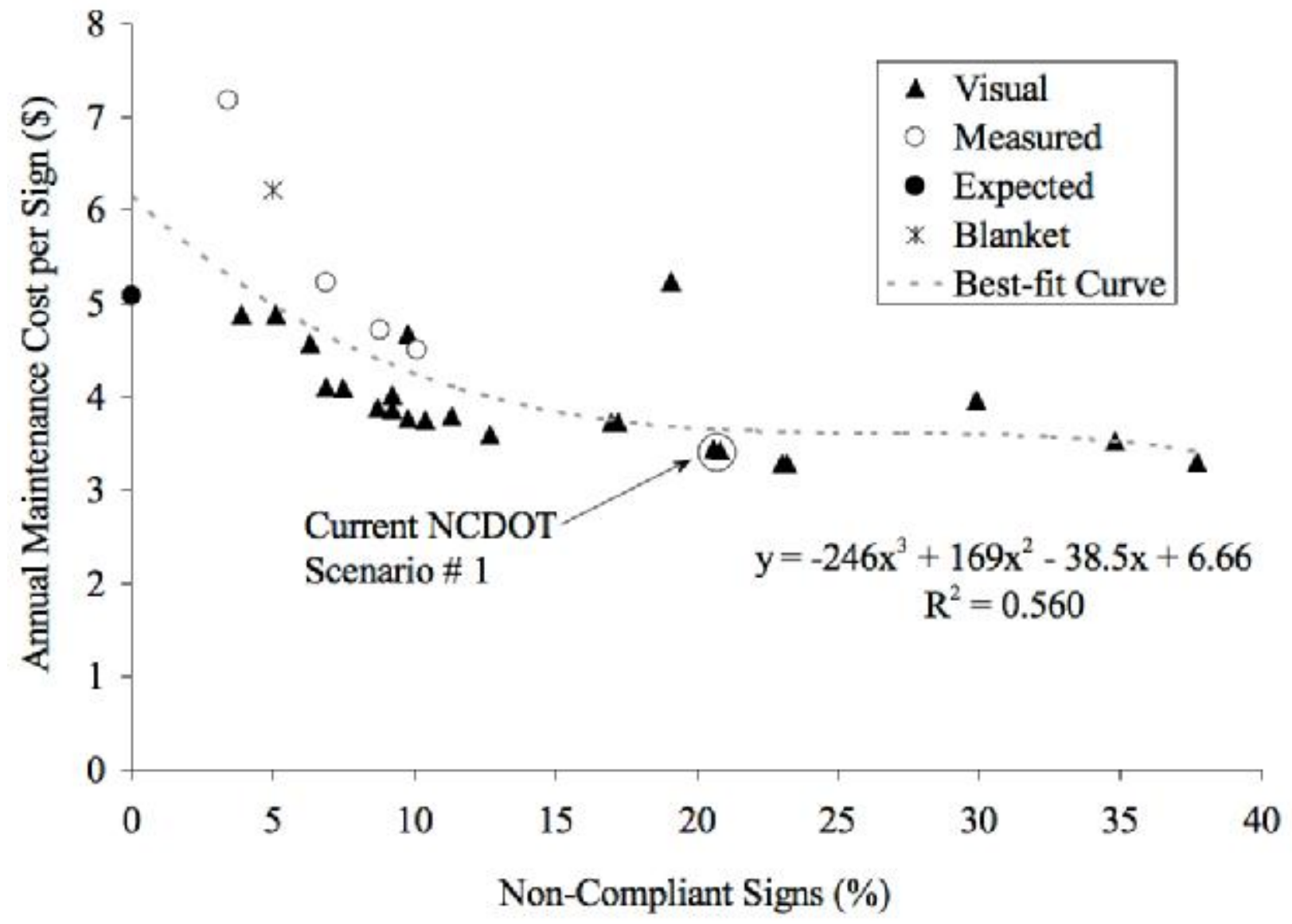

FIGURE 1 Annual maintenance cost per sign vs. percentage of non-compliant signs. 